\title{
CORRIGENDUM
}

\section{International uniform response criteria for multiple myeloma}

BGM Durie, J-L Harousseau, JS Miguel, J Bladé, B Barlogie, K Anderson, M Gertz, M Dimopoulos, J Westin, P Sonneveld, H Ludwig, G Gahrton, M Beksac, J Crowley, A Belch, M Boccadaro, I Turesson, D Joshua, D Vesole, R Kyle, R Alexanian, G Tricot, M Attal, G Merlini, R Powles, P Richardson, K Shimizu, P Tosi, G Morgan and SV Rajkumar on behalf of the International Myeloma Working Group

Leukemia (2006) 20, 2220. doi:10.1038/sj.leu.2404428

Correction to: Leukemia (2006) 20, 1467-1473.

doi:10.1038/sj.leu.2404284

It has been identified by the authors that there was an error in the author list. The following author was omitted in error.

M Cavo, Institute of Hematology and Medical Oncology 'Seràgnoli', University of Bologna, Italy.

The corrected list is mentioned here.
BGM Durie, J-L Harousseau, JS Miguel, J Bladé, B Barlogie, K Anderson, M Gertz, M Dimopoulos, J Westin, P Sonneveld, H Ludwig, G Gahrton, M Beksac, J Crowley, A Belch, M Boccadaro, M Cavo, I Turesson, D Joshua, D Vesole, R Kyle, R Alexanian, G Tricot, M Attal, G Merlini, R Powles, P Richardson, K Shimizu, P Tosi, G Morgan and SV Rajkumar on behalf of the International Myeloma Working Group.

The authors apologize for any inconvenience caused. 